\title{
Identification of Morphological and Pomological Characteristics of Iraq Pomegranate (Punica granatum L.) Variety Salakhani and Comparing with Variety Zivzik
}

\author{
Khabbat H. Al-Jabbarı (iD)1, Mine Pakyürek (iD)*, , Adnan Yaviç (iD)2 \\ ${ }^{1}$ Department of Horticulture, Faculty of Agriculture, Siirt University, Siirt, Turkey \\ ${ }^{2}$ Department of Horticulture, Faculty of Agriculture, Yüzüncü Yıl University, Van, Turkey
}

\begin{abstract}
In this study, morphological and pomological characteristics of Salakhani, local variety of Iraq and Zivzik (Punica granatum L.), local variety of Siirt, were compared. Salakhani variety, which is one of the well-known pomegranate cultivars in Halabja region, has been cultivated for centuries in this region, North of Iraq. Zivzik variety is considered to be one of the important local varieties in Siirt province in the South East of Turkey. Salakhani variety was collected from their natural area in Halabja and Zivzik variety was collected from Zivzik Village in Şirvan. This is the first study comparing both varieties in point of pomological and morphological features. Our study has shown that two varieties are similiar on account of some features on the other hand are also different with regard to some properties. In addition to that the study showed Salakhani has more bigger fruit size and with soft seed than Zivzik pomegranate; conversely, Zivzik cv. has also very juicy fruit and high quality of fruit juice compare with Salakhani. This study has shown the superior characteristics of these two varieties can be the subject of different breeding studies in developing new pomegranate varieties.
\end{abstract}

\section{ARTICLE HISTORY}

Received: July 30, 2019

Revised: September 16, 2019

Accepted: September 25, 2019

\section{KEYWORDS}

Salakhani cv., Zivzik cv., Pomological Properties, Morphological Properties, Pomegranate.

\section{INTRODUCTION}

Pomegranate tree is noted to be one of the oldest ancient and sacred fruit trees in the Mediterranean region. Punica granatum L. is considered to be one of the most important horticultural products and is known in Punicaceae family, which comprises Punica genus includes two species Punica granatum L. and Punica proptopunica Balf [1-4].

In recent years, pomegranate is cultivated and grown naturally and is well adapted to the regional climate in Afghanistan, China, Morocco, Palestine, India, Iraq, Iran, Israel, Italy, Cyprus, Egypt, Syria, Saudi Arabia, Thailand, Tunisia, Turkey as well as being grown in some other countries. Iran is considered to be the main producer country of pomegranate fruit followed by India, Turkey and Spain [5].

Pomegranate species need little chilling. Pomegranate is not damaged by late frost in late spring, but fruit in late varieties can be influenced by early autumn frosts. The annual rainfall of $500 \mathrm{~mm}$ is considered to be sufficient for the growth of pomegranate, especially in the fall and spring months. This information is taken into consideration for the pomegranate growing

CONTACT: Mine PAKYÜREK $₫$ mine.pakyurek@siirt.edu.tr $\equiv$ Department of Horticulture, Faculty of Agriculture, Siirt University, Siirt, TURKEY 
in the appropriate region of Turkey; Mediterranean, Aegean and South Eastern Anatolia Region. However, partial air-conditioning can also be done for pomegranate growing in certain regions [6].

Salakhani variety, which is one of the well-known pomegranate cultivars in Halabja region, has been cultivated for centuries in Halabja is located in the North of Iraq, $15 \mathrm{~km}$ west of the Iranian border, $61 \mathrm{~km}$ southeast of Sulaymaniyah and $241 \mathrm{~km}$ northeast of the capital Baghdad. It is a local pomegranate genotype of high quality grown naturally and well adapted to the regional climate and cultivation in residential areas is an important source of income and survival lihood for regional residents. Villages and districts, which surround Halabja region, are famous for the pomegranate fruit, called as Hanary Hawraman (Hawraman pomegranate).

Zivzik variety is registered and commercially produced pomegranate cultivar in villages (Zivzik, Kapıl1, Sarı Dana and Pirinçli) have microclimate areas and belongs to Şirvan district in Siirt. Zivzik pomegranate, registered in 2008 by the Pistachio Research Institute, by virtue of with big aril, extremely good in terms of taste, aroma and fruit juice quality and it can be stored for 6 months when stored under suitable conditions, is a commonly produced variety.

The aim of this study was to characterize and compare two local pomegranate varieties Salakhani, in Halabja province in north of Iraq, and Zivzik, in southeast of Turkey, selected as the study area, as well to determine pomological and morphological characteristics of both varieties and find out the similarities and differences between them.

\section{MATERIAL and METHODS}

\subsection{Material}

\subsubsection{Geographical structure and climate features of the study area}

The study was carried out in 2015-2016, at the Department of Horticulture, Faculty of Agriculture in Siirt University. Siirt province is located between east longitude $41^{\circ}-57^{\prime}$ and north latitude $37^{\circ}-55^{\prime \prime}$. Siirt province is surrounded by Şırnak and Van in the east, Batman and Bitlis in the north, Mardin and Şırnak provinces in the south. A large part of the territory of the province is covered with mountains. The province has a total area of $6.186 \mathrm{~km}^{2}$ [7]. In Siirt province, that experiences the most significant features of the four seasons, the continental climate prevails. The summers are hot and dry, between June and October precipitation is not observed. More precipitation has been observed in the spring, the amount of moisture with $40 \%$ in normal has reached the value over this rate. In the eastern and northern regions of Siirt province that has much difference between day and night temperatures, the winters are rainy and frosty and the southern and western regions are warm. The wind blowing from the east and northeast at night blows from the south and southwest during the day [7]. The altitude of the city centre of Pervari district is $1.380 \mathrm{~m}$, and agricultural production is performed over 7.300 acres [8]. The 90-year average of Siirt province climate data as shown in Table 1 [9].

Halabja province is located in the southeast of the Sulimanni province. It is situated near the border of Iranian with the city of Halabja and is surrounded by the Hawamian and Sorine mountains in the northeast and north, the Sirwan river in the west, Penguin district in the north, Sharazore district in the northwest, Derbandikhan Lake in the west and southwest. Halabja lies between east longitude $45^{\circ} 59^{\prime} 03.4^{\prime \prime} \mathrm{E}$ and north latitude $35^{\circ} 10^{\prime} 32.8^{\prime \prime} \mathrm{N}$. The elevation is about $695 \mathrm{~m}$ above sea level (MSL) and the average wind speed is $2.3 \mathrm{~m} / \mathrm{s}$ in summer, and $1.4 \mathrm{~m} / \mathrm{s}$ in the winter season. The estimated cultivation area of fruit trees in the region is approximately 2245 hectares [10]. 10 year average (2006-2016) climate data of Halabja province was shown in Table 2 [11]. 
Table 1. The average of climatic data for 90 years (1926-2016) of Siirt province [5].

\begin{tabular}{|c|c|c|c|c|c|c|c|}
\hline Months & $\begin{array}{c}\text { Average } \\
\text { Temperature } \\
\left({ }^{\circ} \mathrm{C}\right)\end{array}$ & $\begin{array}{c}\text { Average } \\
\text { High } \\
\text { Temperature } \\
\left({ }^{\circ} \mathrm{C}\right)\end{array}$ & $\begin{array}{c}\text { Average } \\
\text { Low } \\
\text { Temperature } \\
\left({ }^{\circ} \mathrm{C}\right)\end{array}$ & $\begin{array}{c}\text { Highest } \\
\text { Temperature } \\
\left({ }^{\circ} \mathrm{C}\right)\end{array}$ & $\begin{array}{c}\text { Lowest } \\
\text { Temperature } \\
\left({ }^{\circ} \mathrm{C}\right)\end{array}$ & $\begin{array}{c}\text { Average } \\
\text { Precipitation } \\
(\mathrm{mm})\end{array}$ & $\begin{array}{c}\text { Average } \\
\text { Relative } \\
\text { Humidity } \\
(\%)\end{array}$ \\
\hline January & 2.6 & 6.5 & -0.6 & 19.7 & -19.3 & 97.5 & 77 \\
\hline February & 4.2 & 8.7 & 0.5 & 20.6 & -16.5 & 98.2 & 69 \\
\hline March & 8.2 & 13.2 & 4 & 28.5 & -13.3 & 111 & 65 \\
\hline April & 13.7 & 19.1 & 8.9 & 32.9 & -4.1 & 104.4 & 59 \\
\hline May & 19.3 & 25.2 & 13.5 & 36.2 & 2 & 61.8 & 52 \\
\hline June & 25.9 & 32.1 & 18.9 & 40.2 & 8.2 & 8.8 & 36 \\
\hline July & 30.5 & 37 & 23.4 & 44.4 & 13.1 & 1.6 & 30 \\
\hline August & 30.1 & 36.9 & 23.1 & 46 & 14.4 & 0.9 & 29 \\
\hline September & 25 & 32.1 & 18.7 & 39.9 & 8.5 & 5 & 34 \\
\hline October & 17.9 & 24.3 & 12.7 & 36.6 & 0.3 & 49.6 & 47 \\
\hline November & 10.4 & 15.4 & 6.3 & 26 & -4.1 & 81.4 & 64 \\
\hline December & 4.7 & 8.7 & 1.6 & 24.3 & -14.6 & 95.2 & 72 \\
\hline Total & 16 & 21.6 & 10.9 & 46 & -19.3 & 715.4 & 52.83 \\
\hline
\end{tabular}

Table 2. The average of climatic data for 10 years (2006-2016) of Halabja Province [6].

\begin{tabular}{lccccccc}
\hline Months & $\begin{array}{c}\text { Average } \\
\text { Temperature } \\
\left({ }^{\circ} \mathrm{C}\right)\end{array}$ & $\begin{array}{c}\text { Average } \\
\text { High } \\
\text { Temperature } \\
\left({ }^{\circ} \mathrm{C}\right)\end{array}$ & $\begin{array}{c}\text { Average } \\
\text { Low } \\
\text { Temperature } \\
\left({ }^{\circ} \mathrm{C}\right)\end{array}$ & $\begin{array}{c}\text { Highest } \\
\text { Temperature } \\
\left({ }^{\circ} \mathrm{C}\right)\end{array}$ & $\begin{array}{c}\text { Lowest } \\
\text { Temperature } \\
\left({ }^{\circ} \mathrm{C}\right)\end{array}$ & $\begin{array}{c}\text { Average } \\
\text { Precipitation } \\
(\mathrm{mm})\end{array}$ & $\begin{array}{c}\text { Average } \\
\text { Relative } \\
\text { Humidity } \\
(\%)\end{array}$ \\
\hline January & 7.42 & 11.04 & 2.77 & 16.04 & -2.82 & 97.13 & 56.78 \\
February & 9.18 & 13.69 & 4.89 & 19.89 & -1.24 & 110.43 & 54.6 \\
March & 13.5 & 18.6 & 8.38 & 25.7 & 3.02 & 78.04 & 47.55 \\
April & 18.35 & 23.92 & 12.68 & 31.62 & 6.6 & 80.62 & 45.31 \\
May & 23.97 & 31.69 & 18.88 & 39.51 & 12.54 & 29.71 & 35.7 \\
June & 32.28 & 39.73 & 25.26 & 39.66 & 20.65 & 1.02 & 23.24 \\
July & 35.31 & 42.73 & 28.16 & 45.96 & 24.31 & 0.35 & 27.13 \\
August & 35.26 & 42.77 & 27.9 & 46.29 & 24.21 & 0.12 & 26.98 \\
September & 30.24 & 37.51 & 22.94 & 42.8 & 17.48 & 0.77 & 33.3 \\
October & 23.28 & 28.92 & 17.5 & 36.4 & 11.02 & 67.16 & 35.73 \\
November & 14.66 & 19.22 & 9.18 & 25.23 & 4.67 & 88.29 & 51.22 \\
December & 9.19 & 13.71 & 8.79 & 19.4 & 1.65 & 86.91 & 53.17 \\
Total & 21.05 & 26.96 & 15.61 & 32.38 & 10.17 & 640.08 & 40.89 \\
\hline
\end{tabular}

\subsubsection{Geographical structure and climate features of the study area}

In this experiment, a private orchard of pomegranate Salakhani and Zivzik were selected. Plant age ranged between 20-25 years old trees were selected on the basis of their uniformity in appearance, growth habits and vigour. Salakhani variety is a local pomegranate genotype grown naturally, specifically in Halabja province. Zivzik variety is considered to be one of the local varieties in Siirt province in the southeast of Turkey. Salakhani variety was collected from their natural area by Khabbat H. Al-Jabbari and Zivzik variety was collected from Zivzik Village in Şirvan, Siirt. Salakhani fruits are medium to large size, the peel is thick with reddish to yellow colour, aril full of juice with pink to red colour, they had a good flavour sour-sweet 
taste and fruits can be used for fresh consumption or local production of the concentrated pomegranate juice [12]. Zivzik fruits are small to medium size, the peel is thick with pink to green colour, aril full of juice with pink to dark pink colour, they had a good flavour sour to sour-sweet taste with semi easy in aril separating and seed hard [13].

\subsection{Methods}

\subsubsection{Pomological properties}

Pomegranate genotypes with superior properties were determined according to the selection criteria of fruit and some pomological characteristics were examined. Genotype, fruit weight $(\mathrm{g})$, fruit length $(\mathrm{mm})$, fruit width $(\mathrm{mm})$, fruit juice volume $(\mathrm{mL})$, fruit volume $(\mathrm{mL}$, calyx diameter $(\mathrm{mm})$, calyx length $(\mathrm{mm})$, peel thickness $(\mathrm{mm})$, aril colour, peel colour, number of chamber, appearance of calyx, easiness for aril separating, the taste of fruit, fruit pulp weight (g), fruit shape index and aril yield (\%) were determined. Moreover, Total Soluble Solids (T.S.S) (\%), pH and titratable acid ratio (\%) contents also were measured. Some pomological properties are shown in Figure 1 [14-16].

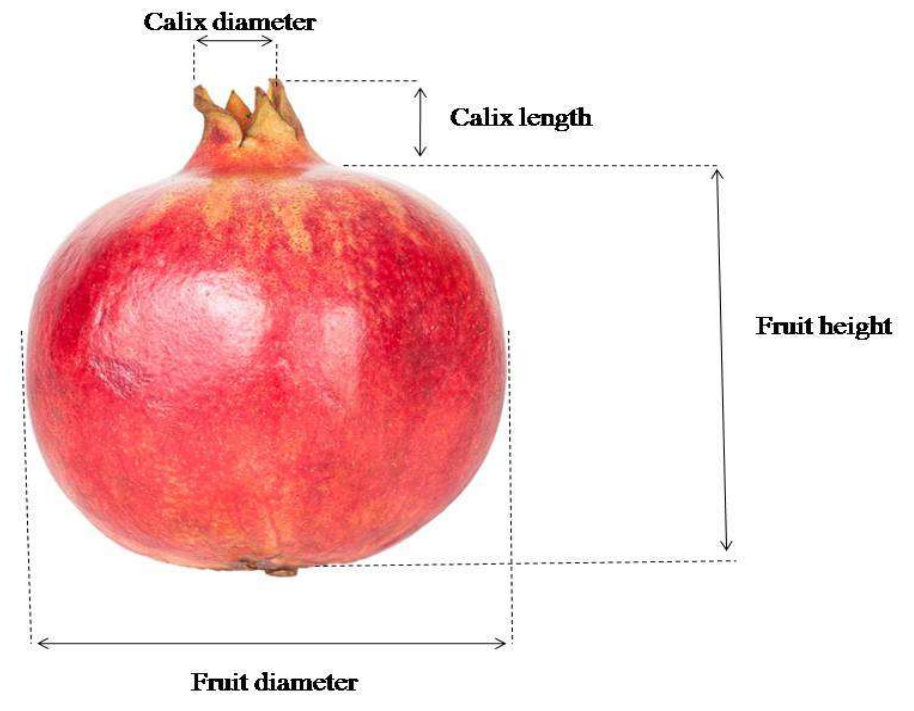

Figure 1. Fruit and calyx sizes: fruit width, fruit height, diameter of calyx, calyx length.

\subsubsection{Field study}

The flowering time of pomegranate fruit in Siirt province starts at the month of May, and the harvested date starts in the middle of the month of October. In order to ensure the best quality the fruit should be picked at the fully ripened stage and it depends on the local climate and pomegranate variety. Whereas, the flowering time of Salakhani variety in Halabja Province begins in the middle of the month of April, and the harvest time starts at the beginning of the month of October, depends on climatic conditions and variety of pomegranate (Figure 2). On each tree, the following morphological and phenological characters were determined: pomegranate local name, tree location, altitude $(\mathrm{m})$, crown height $(\mathrm{cm})$, crown width $(\mathrm{cm})$, trunk number, trunk girth $(\mathrm{cm})$, intensity of branching, cold damage, date of first leafing, flowering date and harvest date. 


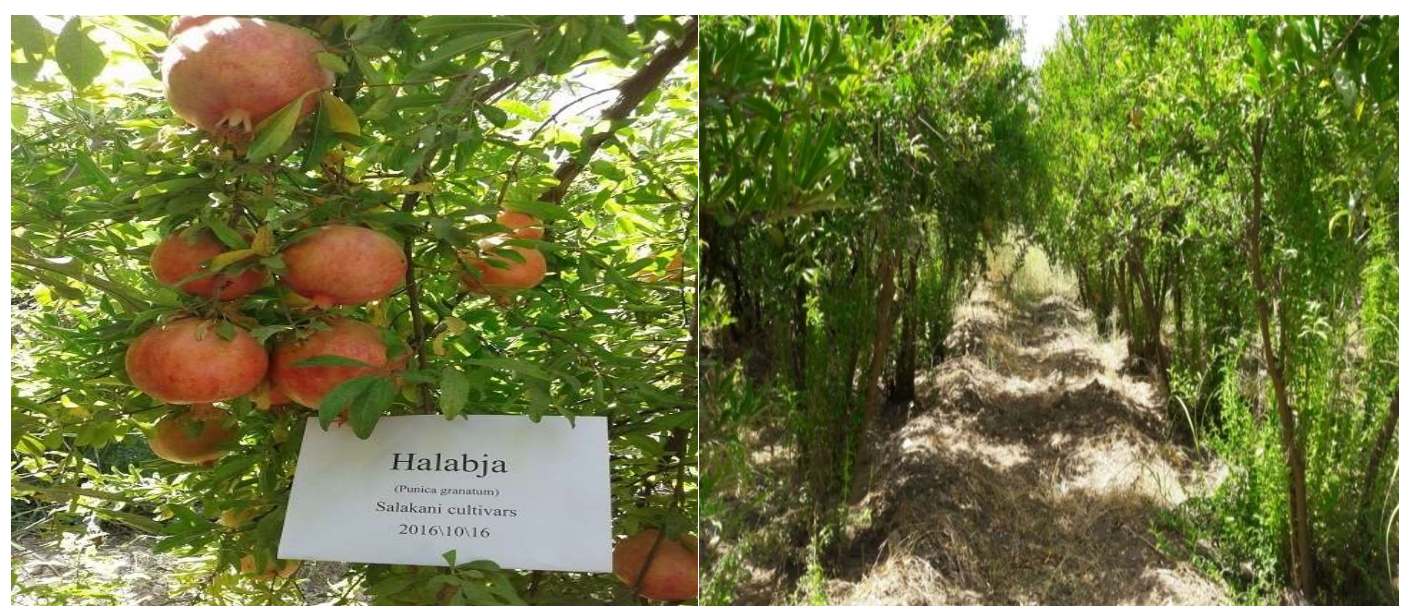

Figure 2. Salakhani pomegranate fruit and appearance of its orchard.

The fruits at commercially ripe stage from two main pomegranate variety 'Salakhani' from North Iraq and 'Zivzik' from Southeast of Turkey were harvested from 20 year-old trees in October 2016. The trees were spaced 4 and $3 \mathrm{~m}$ between and within rows (Zivzik trees are seen in Figure 3). Both cultivars were grown under the different geographical conditions. 15 fruits were picked up randomly from each cultivar as a sample were randomly collected at morning and then put in cooler bags to be quickly transferred to the laboratory. The fruit samples were collected during the maturity stage and the analyses were performed in the laboratory of the Faculty of Agriculture, Department of Horticulture in Siirt University. All fruits were first flushed by tap water before the peel, pulp and seed fractions were carefully separated. The peel and pulp were separated manually after measurement of fruit fresh mass and volume. 15 fruits were maintained for each analysis and the results were presented average of the fruits values.
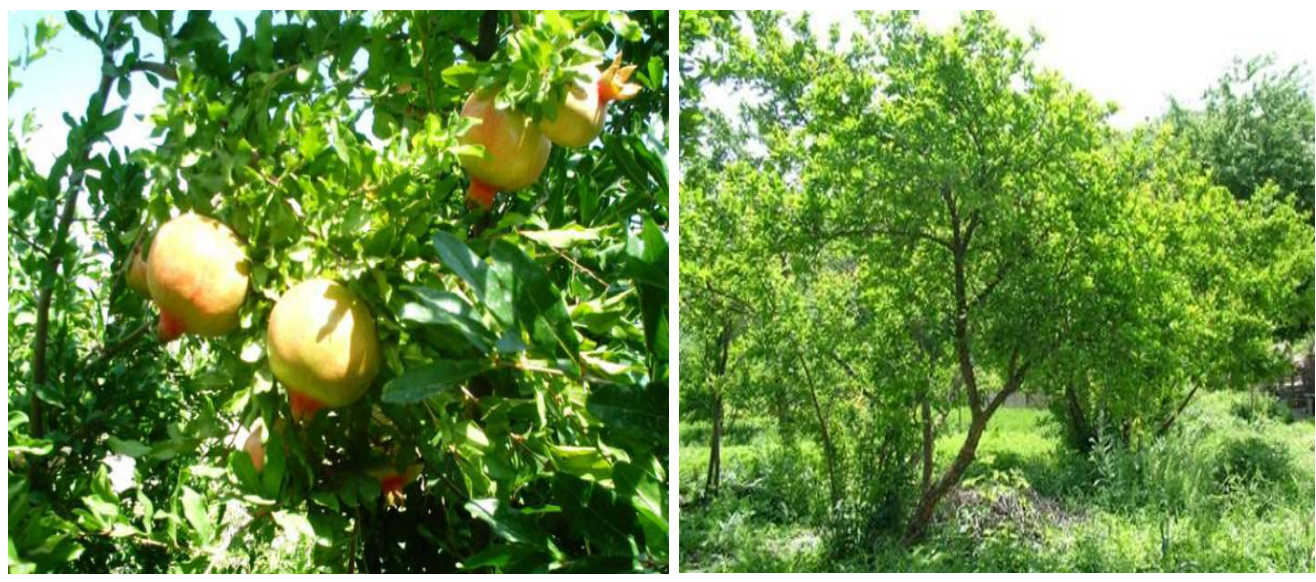

Figure 3. Zivzik pomegranate fruit and appearance of its orchard.

\section{RESULTS and DISCUSSION}

\subsection{The Results Obtained from The Field}

Studies were carried out in the private orchard in Halabja province. The information were obtained from the questionnaires filled in for Salakhani variety is summarised below. Pomegranates local variety grown in the main production area of Halabja Province and surrounding area. It covers a wide areas of this region, Halabja Province is also well known for pomegranate production and the high quality of its fruits and some other fruits due to appropriate climatic conditions and these areas are ideal places for pomegranate growing. 
This area is characterised by a highly fertile and non-stressful conditions. Furthermore, it is considered to be rich in nutrient elements. For this reason, commercial fertilisers are rarely used, while, that the farmyard manure (organic fertilizers) is generally used as a plant fertiliser. Nevertheless, a common fertilizer application is also performed. Fertilizers are commonly used for growing all the plants, with application rates depending on soil fertility and economic conditions of the farmers. In orchards, plants are normally trained to a multiple trunks, in order to reduce risk of total tree loss. Most of the pests deployed in the region such as aphids and trunk borers. Fruit cracking and splitting phenomenon were observed in the region.

Table 3. Physical properties of pomegranate fruit.

\begin{tabular}{lcc}
\hline \multicolumn{1}{c}{ Fruit Features } & Salakhani variety & Zivzik variety \\
\hline Fruit weight $(\mathrm{g})$ & $389.43-578.51$ & $129.8-379.5$ \\
Fruit height $(\mathrm{mm})$ & $87.70-99.49$ & $59.50-82.50$ \\
Fruit width $(\mathrm{mm})$ & $88.28-103.11$ & $66.70-90.50$ \\
Fruit volume $(\mathrm{mL})$ & $350-600$ & $250-400$ \\
Calyx radius $(\mathrm{mm})$ & $6.4-8.74$ & $7.7-8.9$ \\
Calyx length $(\mathrm{mm})$ & $21.56-23.45$ & $15.7-22.4$ \\
Fruit juice volume $(\mathrm{mL})$ & $180-250$ & $60-85$ \\
Fruit pulp and peel weight $(\mathrm{g})$ & $205-287$ & $85-220$ \\
Fruit taste & sour-sweet & sour-sweet \\
Aril colour & Pink & dark pink \\
Seed hardness & Hard & semi-hard \\
Aril yield (\%) & $59.10-69.04$ & $51.17-61.12$ \\
Upper fruit peel colour & Light pink- pink & Red \\
Bottom fruit peel colour & pink & Yellow \\
Peel thickness (mm) & $2.11-2.99$ & $2.75-4.00$ \\
Upper chamber number & 5 to 6 & 5 to 7 \\
Bottom chamber number & 3 to 4 & 4 to 5 \\
Appearance of calyx & Clear & semi-clear \\
Easiness of aril separating & Easy & semi-easy \\
Fruit shape index & $0.96-0.99$ & $0.89-0.91$ \\
\hline
\end{tabular}

\subsection{Pomological Properties}

In this study, two types of pomegranate fruit were selected to examine the physical features, and the averages of the results obtained are shown below. Fruit weight of Salakhani fruit was found to be between 389.43-578, $51 \mathrm{~g}$, while, that the weight of Zivzik fruit ranged between 129.8-379.5 g (Table 3). As demonstrated in Table 3 fruit height of Salakhani variety was found to be between $87,70-99,49 \mathrm{~mm}$. Whereas, the fruit height of Zivzik variety ranged between 59.50-82.50 mm. Fruit width of Salakhani variety was found to be between 88.28$103.11 \mathrm{~mm}$, while; the fruit width of Zivzik variety ranged between $66.70-90.50 \mathrm{~mm}$ (as shown in Table 3). Fruit volume of Salakhani variety was found to be between 350-600 mL, while the fruit volume of Zivzik variety was found to be between $250-400 \mathrm{~mL}$ (as shown in Table 3). Calyx radius of Salakhani variety ranged between $6.4-8.74 \mathrm{~mm}$, while in Zivzik variety it ranged between 7.7- $8.9 \mathrm{~mm}$. Calyx length of Salakhani variety ranged between 21.56-23.45 $\mathrm{mm}$ and in Zivzik variety it ranged between 15.7-22.4 $\mathrm{mm}$. Fruit juice volume of Salakhani variety ranged between $180-250 \mathrm{~mL}$, while in Zivzik variety it was found to be between $60-85$ $\mathrm{mL}$. Fruit pulp of Salakhani variety ranged between $205-287 \mathrm{~g}$, while the fruit pulp of Zivzik variety ranged between 85-220 g (Table 3). Fruit taste of Salakhani and Zivzik varieties were 
sour sweet (Table 3). Aril colour of Salakhani pomegranate is pink, while, the aril colour of Zivzik pomegranate is dark pink. As demonstrated in Table 3 seed hardness of Salakhani variety is hard, while the seed hardness of Zivzik variety is semi-hard. Aril yield of Salakhani variety ranged between 59.10-69.04 \%, while the aril yield of Zivzik variety was found to be between $51.17-61.12 \%$. Upper side colour of Salakhani variety is light pink into pink, while the upper side colour of Zivzik variety is red. Bottom side colour of Salakhani variety is pink, while the bottom side colour of Zivzik variety is yellow. Peel thickness of Salakhani variety is found to be between 2.11-2.99 mm, while the peel thickness of Zivzik variety is found to be between 2.75-4.00 mm. Upper chamber number of Salakhani variety is found to be between 5-6, while the upper chamber number of Zivzik variety is between 5-7. Bottom chamber number of Salakhani variety is found to be between 3-4, while bottom chamber number of Zivzik variety ranged between 4-5. The appearance of calyx of Salakhani variety is clear and the appearance of calyx of Zivzik variety is semi-clear (as shown in Table 3). Aril separating in Salakhani variety is easy, while the aril separating in Zivzik variety is semi-easy. Fruit shape of Salakhani variety was found to be between 0.96-0.99, while the fruit shape of Zivzik variety was found to be between 0.89-0.91.

Soluble solids ratio (\%) of Salakhani variety was found to be between 15.1-16.1\% while the soluble solids ratio (\%) of Zivzik variety was found to be between 13-17\% (as shown in Table 4). As seen in Table $4 \mathrm{pH}$ of fruit juice of Salakhani cultivars was found to be between 3.05-3.19\%. While, in Zivzik cultivars it was found to be between 3.6-4.0 (Table 4). Titratable acid ratio in the fruit juice of Salakhani variety was ranged between $0.9-1.3 \%$. Whereas, in Zivzik variety it was found to be between $0.4-0.8 \%$. The mean values of the pomological characteristics of both varieties are given in Table 5 and Table 6 .

\subsection{Discussion}

Gündoğdu et al. [13], carried out an experiment on pomegranate genotypes planted in Siirt province. They investigated pomological properties of these genotypes such as fruit weights, fruit heights, fruit diameters, fruit volumes, fruit juice amounts, fruit densities, seed weights, calyx heights, calyx half-diameters, total soluble solid (TSS), $\mathrm{pH}$, fruit shape index, total acidity. Valus of these properties ranged between the given numbers respectively $161.45-$ $302.35 \mathrm{~g} ; 60.79-78.67 \mathrm{~mm}$; $67.27-86.92 \mathrm{~mm} ; 177.5-305.0 \mathrm{~mL} ; 69-121 \mathrm{~mL} ; 0.84-1.17 \mathrm{~g} \mathrm{~cm}-3$; 80.00-162.35 g; 16.58-34.64 mm; 9.32-14.27 mm; $12-16$ brix; 3.63-5.87; 0.84-1.03; and 0.47$1.08 \%$. In addition to that, in this study the other pomological features of pomegranate genotypes were observed such as fruit taste, seed hardness, seed colour, easiness in separating arils, sub-skin colour, upper skin colour, compartment appearance, upper fruit compartment, sub-fruit compartment and fruit pulp weights as well.

Mars and Marrakchi [17], studied thirty pomegranate (Punica granatum L.) accessions to determine the overall degree of polymorphism and to detect similarities among the genotypes grown naturally in Tunisia. In the study, fruit weights ranged from $196 \mathrm{~g}$ to $673 \mathrm{~g}$; fruit heights ranged from $46 \mathrm{~mm}$ to $96 \mathrm{~mm}$; fruit diameters ranged from $57 \mathrm{~mm}$ to $114 \mathrm{~mm}$; peel thickness ranged from to $2.4 \mathrm{~mm}$ to $6.1 \mathrm{~mm}$; calyx length ranged from $12 \mathrm{~mm}$ to $21 \mathrm{~mm}$; fruit juice amounts ranged from $72 \mathrm{~mL}$ to $100 \mathrm{~mL}$; the TSS ranged from $13.3 \%$ to $16.9 \%$; pH ranged from 0.93 to 4.6; the titratable acidity ranged from 0.25 to 3.17 .

Again in another experiment Gündoğdu et al. [18] examined certain chemical and pomological features of standard pomegranate varieties cultured in Turkey. These features are such as fruit weights, fruit height, fruit diameter, fruit volume, fruit juice, fruit densities, total soluble solid content (T.S.S), $\mathrm{pH}$, total acidity. Values are in the following ranges 251.01$530.25 \mathrm{~g} ; 60.30-89.97 \mathrm{~mm}$; 75.57-100.68 mm; 230.00-542.50 mL; 106.66-186.00 mL; 0.92$1.19 \mathrm{~g} \mathrm{~cm}-3 ; 11.50-14.62 \% ; 3.45-4.71$ and $0.19-1.17 \%$. Furthermore, they also investigated fruit taste, aril colour, easiness of aril separating, seed hardness, peel colour, upper peel colour, 
upper chamber number, bottom chamber number, calyx number, appearance of calyx in their study.

Table 4. Chemical properties of pomegranate fruit.

\begin{tabular}{lcc}
\hline \multicolumn{1}{c}{ Fruit Features } & Salakhani variety & Zivik variety \\
\hline T.S.S (\%) & $15.1-16.1$ & $13-17$ \\
pH & $3.05-3.19$ & $3.6-4.0$ \\
Titrable acidity (\%) & $0.9-1.3$ & $0.4-08$ \\
\hline
\end{tabular}

Table 5. Phenology, flowering and tree characteristics of Salakhani variety.

\begin{tabular}{|c|c|c|c|}
\hline CULTIVAR NAME & $\begin{array}{c}\text { Salakhani } \\
\text { cultivars }\end{array}$ & Fruit Features & Value \\
\hline Name of location & Halabja & Fruit weight (gr) & 502.34 \\
\hline Location of orchard & Byawella & Fruit height (mm) & 94.01 \\
\hline Local name & Salakhani & Fruit width (mm) & 95.48 \\
\hline Altitude (m) & $695 \mathrm{~m}$ & Fruit volume $(\mathrm{mL})$ & 470 \\
\hline The status of irrigation & $\begin{array}{l}\text { watered in } \\
\text { summer }\end{array}$ & Calyx diameter (mm) & 15.25 \\
\hline \multirow[t]{3}{*}{ Status of wind } & middle & Calyx length (mm) & 22.7 \\
\hline & & Fruit juice volume $(\mathrm{mL})$ & 220 \\
\hline & & Fruit pulp and peel weight (g) & 251 \\
\hline TREE FEATURES & & Fruit taste & sweet-sour \\
\hline Crown height (mm) & 231 & Peel colour & light pink- pink \\
\hline Crown width (mm) & 460 & Seed hardness & hard \\
\hline Trunk number (No) & 5 & Aril yield (\%) & 68.04 \\
\hline Trunk girth (cm) & 18 & Weight of 100 arils (g) & 42.3 \\
\hline Density of the branches & middle & Upper fruit peel colour & pink- light pink \\
\hline \multirow[t]{2}{*}{ Cold damage } & No & Bottom fruit peel colour & pink \\
\hline & & Peel thickness (mm) & 2.72 \\
\hline PHENOLOGICAL OBSERVATIONS & & Upper chamber number & 5.8 \\
\hline Date of first leafing & $18^{\text {th }}$ March & Bottom chamber number & 3.4 \\
\hline Flowering time & $22^{\text {th }}$ April & Appearance of calyx & clear \\
\hline \multirow[t]{5}{*}{ Harvest date } & $5^{\text {th }}$ October & Easiness of aril seperating & easy \\
\hline & & Fruit shape index & 0.984 \\
\hline & & T.S.S (\%) & 15.6 \\
\hline & & $\mathrm{pH}$ & 3.12 \\
\hline & & Titrable acid ratio (\%) & 1.1 \\
\hline
\end{tabular}

Muradoğlu et al. [19], conducted an experiment to describe the desirable pomological traits of 46 pomegranate genotypes selected from Çukurca district in Hakkari. The data were recorded as follows: fruit weights ranged from $131 \mathrm{~g}$ to $337 \mathrm{~g}$, fruit height ranged from 60.0 $\mathrm{mm}$ to $81.0 \mathrm{~mm}$, fruit width ranged from $30.8 \mathrm{~mm}$ to $88.9 \mathrm{~mm}$, calyx length ranged from 11.0 $\mathrm{mm}$ to $26.1 \mathrm{~mm}$ and calyx diameter ranged from $11.2 \mathrm{~mm}$ to $18.1 \mathrm{~mm}$. In addition, the total soluble solid content was between $12.2 \%$ and $17.6 \%$. The values of $\mathrm{pH}$ ranged from 2.6 to 3.8 . The acidity was between $1.5 \%$ and $2.9 \%$. Genotypes had green or yellow coloured bottom skins, red or pink coloured aril, soft, semi-hard and hard seeds. Their aril percentages changed between $49.5 \%$ and $71.5 \%$. 
From Turkey some researchers, Usanmaz et al. [20], observed that the yield and pomological properties of three pomegranate cultivars: Wonderful, Acco and Herskovitz cultivated in Cyprus. According to findings of this experiment, the highest fruit weight and second highest yield belongs to Wonderful cultivar (481.12 g/fruit and $14.17 \mathrm{~kg} / \mathrm{tree})$. The second highest fruit weight and highest yield belongs to Herskovitz (431.04 g/fruit and 15.44 $\mathrm{kg} /$ tree $)$. The lowest fruit weight and yield belongs to Acco $(350.31 \mathrm{~g} /$ fruit and $11.43 \mathrm{~kg} / \mathrm{tree})$. Acco had the highest juice content followed by Wonderful and Herskovitz $(40.22 \%>35.60 \%$ $>29.42 \%)$. Wonderful had the highest juice content (5.05 L/tree). Juice content per tree for Acco and Herskovitz was determined to be $4.58 \mathrm{~L}$ and $4.53 \mathrm{~L}$, respectively.

Table 6. Phenology, flowering and tree characteristics of Zivzik variety.

\begin{tabular}{|c|c|c|c|}
\hline CULTIVAR NAME & $\begin{array}{c}\text { Zivzik } \\
\text { Cultivars }\end{array}$ & Fruit FeaturesValue & Value \\
\hline Name of location & Siirt & Fruit weight (g) & 233.8 \\
\hline Orchard location & $\begin{array}{c}\text { Şirvan/ Zivzik } \\
\text { Vill. }\end{array}$ & Fruit height $(\mathrm{mm})$ & 69.23 \\
\hline Local name & Zivzik & Fruit width $(\mathrm{mm})$ & 76.26 \\
\hline Altitude (m) (MSL) & 850 & Fruit volume (mL) & 225 \\
\hline The status of irrigation & Watered & Calyx diameter (mm) & 16.4 \\
\hline \multirow[t]{2}{*}{ Status of wind } & middle & Calyx length (mm) & 19.75 \\
\hline & & Fruit juice volume $(\mathrm{mL})$ & 75 \\
\hline TREE FEATURES & & Fruit pulp and peel weight (g) & 119.33 \\
\hline Crown height $(\mathrm{cm})$ & 340 & Fruit taste & sweet \\
\hline Crown width $(\mathrm{cm})$ & 350 & Aril colour & dark pink \\
\hline Trunk number (No) & 2 & Seed hardness & semi-hard \\
\hline Trunk girth $(\mathrm{cm})$ & $40-16$ & Aril yield (\%) & 54.17 \\
\hline Density of the branches & middle & Weight of 100 arils (g) & 45.5 \\
\hline \multirow[t]{2}{*}{ Cold damage } & No & Upper fruit peel colour & red \\
\hline & & Bottom fruit peel colour & yellow \\
\hline PHENOLOGICAL OBSERVATIONS & & Peel thickness (mm) & 3.25 \\
\hline Date of first leafing & 13th April & Upper chamber number & 5 \\
\hline Flowering time & 13th May & Bottom chamber number & 4 \\
\hline \multirow[t]{6}{*}{ Harvest date } & 18th October & Appearance of calyx & semi-clear \\
\hline & & Easiness of aril separating & semi-easy \\
\hline & & Fruit shape index & 0.873 \\
\hline & & T.S.S (\%) & 16.5 \\
\hline & & $\mathrm{pH}$ & 3.54 \\
\hline & & Titrable acid ratio (\%) & 0.6 \\
\hline
\end{tabular}

Polat et al. [21], conducted an experiment in Hatay, during which the following results were obtained: fruit weight ranged from $250 \mathrm{~g}$ to $461 \mathrm{~g}, 100$ aril weight ranged from $29 \mathrm{~g}$ to 50 $\mathrm{g}$, fruit height ranged from $69 \mathrm{~mm}$ to $83 \mathrm{~mm}$, fruit width ranged from $80 \mathrm{~mm}$ to $94 \mathrm{~mm}$, peel thickness ranged from $3.7 \mathrm{~mm}$ to $4.3 \mathrm{~mm}$, aril yield ranged from 54 to $73 \%$, TSS rates ranged from 14 to $15 \%$ and acidity ranged between 0.3 and $3.9 \%$. In another study, Y1lmaz et al. [22] was carried out on the regional adaptation of pomegranate in the Mediterranean Region and the following results were obtained fruit width was $92-104 \mathrm{~mm}$, fruit height was $79-91 \mathrm{~mm}$, fruit weight was $411-568 \mathrm{~g}$, (T.S.S) was $13-16 \%$ and acidity $\%$ ranged between $0.13-1.63 \%$. 
In her study, Gözlekçi [23] examined the characteristics of the fruit, and a relationship in the same direction was determined between fruit diameter with fruit weight, fruit diameter with fruit volume, the volume of fruit with fruit weight, fruit length with fruit width, fruit length with fruit weight and juice yield with aril yield, while there was an opposite relationship between the amount of the peel with aril yield, aril yield with TSS and acidity with TSS.

Appropriate pomegranate varieties have been developed in the internal and external markets as a result of breeding works. The peel colour should be red; titratable acidity less than $1 \%$ (sweet), titratable acidity ranging from 1 to $2 \%$ (sour-sweet), titratable acid ratio more than $2 \%$ (sour) [24]. Muradoğlu et al. [20], conducted an experiment on 45 types of pomegranate fruit in Çukurca, and the following results were obtained: weight was 131-337 g, $\mathrm{pH}$ value was 2.60-8.80, titratable acidity rate ranged between 1.50-2.90 \%. Türkmen and Ekşi [25], collected pomegranate varieties (Hicaz, Devedişi, Katırbaşı, Ernar, Fellahyemez, Ekşilik, Aşınar) from different provinces of Turkey (Izmir, Gaziantep, Adana, Mersin, Aydın, Antalya, Muğla, Kilis) with the average fruit weight of $374.9 \mathrm{~g}$, peel ratio of $50 \%$, aril ratio of $49.9 \%$, juice efficiency of $34.7 \%$ and fruit juice content of $8.3 \%$ when obtained just from the aril.

Tehranifar et al. [26], searched 20 types of Iranian pomegranate in their experiment to define the physicochemical features of these types. In their experiment, fruit weight ranged between 196.89-315 g, fruit length ranged between $69.49-81.56 \mathrm{~mm}$, fruit diameter ranged between $64.98-86.88 \mathrm{~mm}$.

Y1ldiz et al. [27], conducted a study in Hizan. In their study, fruit weight was 192-388 g, fruit length was $62-78 \mathrm{~mm}$, fruit diameter was $68-90 \mathrm{~mm}$, the number of sepals was $5-8$, fruit juice rate was $28-55 \%$, peel thickness was $1.3-2.8 \mathrm{~mm}$, TSS was $10-17 \%$ and acidity ranged between 0.37-4.3\%. Tibet and Onur [17], selected 35 pomegranate types from the Aegean Region and South East Anatolia and examined their phenological and pomological characteristics. Fruit weight ranged between $223-493 \mathrm{~g}$, fruit width ranged between $78-102 \mathrm{~mm}$, fruit length ranged between $67-88 \mathrm{~mm}$, T.S.S ranged between $12-16 \%$, aril yield ranged between $41-64 \%$ and the total acidity ranged between $0.19-2.38 \%$.

Numerous studies have been conducted by various researchers so far to investigate the pomological properties and selection of pomegranate. The above-mentioned studies show that pomegranate genotypes grown in nearby geographies have similar and different characteristics as in Salakhani and Zivzik varieties (Figure 4). Detection of these features is extremely important in terms of increasing genetic diversity.
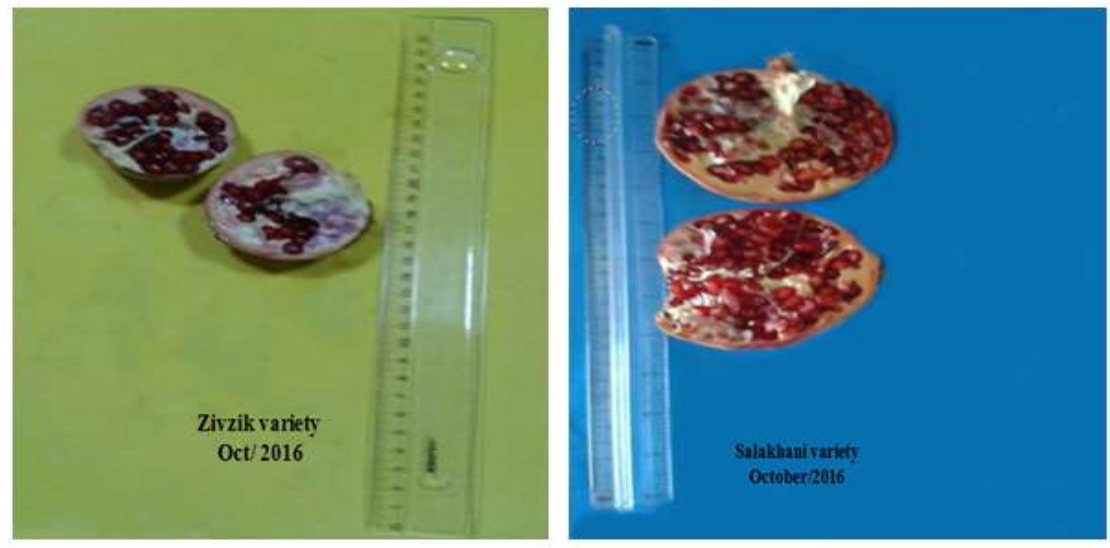

Figure 4. Longitudinal section of pomegranate varieties.

\section{CONCLUSION}

Pomegranate fruit specifications of Salakhani and Zivzik varieties can be summarised as follows: Fruit of Salakhani cultivars were of middle to large size, with the weight of 389.43- 
$578.51 \mathrm{~g}$ their peel thickness ranged between 2.11-2.99 mm, peel colour was pink into light pink, aril colour was pink, they had a good flavour and sour-sweet taste, aril separating is easy, appearance of the calyx is clear, fruit juice volume is ranged between $180-250 \mathrm{~mL}$, fruits can be used for fresh consumption or local production of the concentrated pomegranate juice called Ruba Hanar. The harvesting of Salakhani cultivars begins at the beginning of the month of October.

Zivzik variety is characterised by its small-to-middle size, with the weight of 129.8-379.5 $\mathrm{g}$, peel thickness ranging between $2.75-4.00 \mathrm{~mm}$, fruit juice volume ranging between $60-85 \mathrm{~mL}$, peel colour is red-yellow colour, dark pink aril colour, a good flavour and sour-sweet taste, aril separating is semi-easy and appearance of the calyx is semi-clear. The harvesting of Zivzik variety begins in the middle of October, fruits can be used for fresh consumption or making the pomegranate juice. If we compare both varieties in terms of pomological properties such as size, easiness of aril separating, number of chamber, fruit volume, weight, peel thickness and fruit juice volume; could conclude that Salakhani variety is superior to Zivzik variety. Whereas, Zivzik variety was found to be superior to Salakhani variety in terms of T.S.S and pH of fruit juice.

As a result, Salakhani variety was determined to be superior to Zivzik variety; therefore, we recommend more studies on pomegranate fruit (Salakhani) to investigate the components of pomegranate fruit such as vitamins and other elements. Because of the large number of pomegranate (Punica granatum L.) variety in the North of Iraq, we recommend further study on Iraq pomegranate varieties in terms of pomological properties. Both varieties have distinguished features in terms of pomological properties. The fruits of the Salakhani variety are larger than the fruits of the Zivzik variety. On the other hand, the taste and aroma of Zivzik variety is very good and fruit juice quality is higher. For that reason, the superior aspects of the varieties identified in our study should be used in breeding studies for the development of new pomegranate genotypes. Breeding works towards the development of new pomegranate varieties, both Iraq and Turkey is important in terms of orcharding.

\section{Acknowledgement}

This study is a part of Ms Thesis belongs to Khabbat H. AL-JABBARI and was presented in ISHS, IV. International Symposium on Pomegranate and Minor Mediterranean Fruits (18-22 September 2017, Valencia-İspanya) as abstract-poster.

\section{ORCID}

Khabbat H. A1-Jabbar1 (D) https://orcid.org/0000-0002-5638-5304

Mine Pakyürek (iD https://orcid.org/0000-0002-3753-2532

Adnan Yaviç (DiD https://orcid.org/0000-0003-2609-2815

\section{REFERENCES}

[1]. Popenoe, W. (1974). Manual of tropical and subtropical fruits. The macmillan company, pp: $375-383$.

[2]. Samir, Z., El-Agamy Rafat, AA., Mostafa Mokhtar, M., Shaaban, El-Mahdy, M.T. (2009). In vitro propagation of manfalouty and nab elgamal pomegranate cultivars research. $J$. Agric. Biol. Sci., 5(6), 1169-1175.

[3]. Samir, Z. (2010). In vitro salt and drought tolerance of manfalouty and nab el-Gamal pomegranate cultivars. Australian Basic Appl. Sci., 4(6), 1076-1082.

[4]. Stover, E., Mercure, E.W. (2007). The pomegranate: A new look at the fruit of paradise, HortScience, 42(5), 1088-1092.

[5]. Owis, S.J. (2010). Rooting response of five pomegranate varieties to Indole butyric acid concentration and cuttings age. Pakistan Journal of Biological Sciences, 13(2), 51-58. 
[6]. Nar. Retrieved at 01.06.2011 from www.batem.gov.tr/urunler/meyvelerimiz/nar/nar.htm

[7]. Agriculture master plan of Siirt. Retrieved at 12.04.2003 from https://siirt.tarimorman.gov tr

[8]. Firat, M. (2002). A research on bahçesaray and environmental flora (Master Thesis, Yüzüncü Y1l University, Van). Retrieved at 10.05.2016 from: https://www.tez.yok.gov.tr

[9]. Climatic data for 90 years of Siirt province. Retrieved at 21.03.2016 from http://www.mgm.gov.tr/veridegerlendirme/il-ve-ilceler- atistik.aspx.siirt

[10]. Alaadin, Ata M. (2008). Halabja district regional geographical study. 1st Ed. Kurdology Center Publishing, Halabja, Iraq, p. 110.

[11]. Climatic data for 10 years of Halabja provience. Retrieved at 15.05.2016 from $\mathrm{http} / / \mathrm{www}$.agrometeorology.gov.iq

[12]. Al-Jabbari, A. M.O. (2007). Effect of $\mathrm{GA}_{3}$ and some nutrients of pomegranate fruit (Punica granatum L.) Splitting and storability cv. Salakhani (M.Sc. Thesis, University of Sulaimani, Sulimanni). Retrieved at 10.05.2016 from: http://www.sulimanni.edu.iq/thesi s.

[13]. Gündoğdu, M., Yilmaz, H., Şensoy, R. İ. G., Gündoğdu, Ö. (2010). Pomological characteristics of pomegranate grown in Şirvan (Siirt) region. Yüzüncü Yll University, Tarım Bilimleri Dergisi, 20(2), 138-143.

[14]. Onur, C. (1983). Selection of mediterranean region pomegranate (PhD Thesis, Çukurova University, Adana). Retrieved at 01.06.2016 from: http://www.tez.yok.gov.tr

[15]. Yılmaz, H., Ayanoglu, H., Yildiz, A. (1995). Investigations on the adaptation of some pomegranate species in Erdemli conditions in the Aegean Region, Adana, Turkey. II. National Horticulture Congress, 3-6 October, p.691-695.

[16]. Tibet, H., Onur, C. (1999). Pomegranate (Punica granatum L.) type adaptation in Antalya, Ankara, Turkey. III. National Horticultural Congress. 14-17 September, p. 31-35.

[17]. Mars, M., Marrakchi, M. (1999). Diversity of pomegranate (Punica granatum L.) germplasm in Tunisia. Genetic Resources and Crop Evolution., 46(5), 461-467.

[18]. Gündoğdu, M., Yilmaz, H., Canan, İ. (2015). Physicochemical characterization of pomegranate (Punica granatum L.) varieties and genotypes. Uluslararasi Tarım ve Yaban Hayatı Bilimleri Dergisi., 1(2), 57-65.

[19]. Muradoğlu, F., Balta, F. M., Özrenk, K. (2006). Pomegranate (Punica granatum L.) genetic resources from Hakkari, Turkey. Research Journal of Agricultural and Biological Sciences., 2, 520-525.

[20]. Usanmaz, S., Kahramanoğlu, I., Y1lmaz, N. (2014). Yield and pomological characteristics of three pomegranate (Punica granatum L) cultivars: wonderful, Acco and Herskovitz. Am J Agric For., 2, 61-65.

[21]. Polat, A. A., Durgaç, C., Kamiloglu, Ö., Mansuroglu, M. (1999). Studies on the Determination of the Pomological Characteristics of some Pomegranates grown in Kirıkhan District of Hatay. Ankara, Turkey. III. National Horticulture Congress. 14-17 September, p. 746-750.

[22]. Y1lmaz, H., Sen, B., Y1ld1z, A. (1992). Regional adaptation of selected pomegranates in mediterranean region. İzmir, Turkey. I. National Horticulture Congress. 13-16 October, p.449-452.

[23]. Gözlekçi, S. (1997). Investigations on fertilization, fruit development and maturation of hicaz nar (Punica granatum L.). (PhD Thesis, Akdeniz University, Antalya). Retrieved at 01.04.2016 from: http://www.tez.yok.gov.tr

[24]. Onur, C., Pekmezci, M., Tibet, H., Erkan, M., Gözlekçi (Kuzu), S., Tandoğan, P. (1992). A Research on the cold conservation of hicaz pomegranates. İzmir, Turkey. I. National Horticulture Congress. 13-16 October, p. 449-452. 
[25]. Türkmen, I., Ekşi, A. (2010). Brix degree and sorbitol/xylitol level of authentic pomegranate (Punica granatum L.) Juice. Food Chemistry, 127, 1404-1407.

[26]. Tehranifar, A., Zarei, M., Nemati, Z., Esfendiyari, B. and Vazifeshenas, M.R. (2010). Investigation of physico-chemical properties and antioxidant activity of twenty iranian pomegranate (Punica granatum L.) cultivars. Sci. Hortic., 126, 180-185.

[27]. Yıldız, K., Muradoğlu, F., Oguz, H. İ., Y1lmaz, H. (2003). Pomological features of the pomegranates growing in Hizan. Antalya, Turkey. IV. National Horticulture Congress. 08-12 September, p. 238-240. 